doi: $10.2306 /$ scienceasia1513-1874.2012.38.323

\title{
Use of organic fertilizer on paddy fields to reduce greenhouse gases
}

\author{
Pantawat Sampanpanish $^{\mathrm{a}, \mathrm{b}}$ \\ a Environmental Research Institute, Chulalongkorn University, Bangkok 10330 Thailand \\ b Centre of Excellence for Environmental and Hazardous Waste Management, Chulalongkorn University, \\ Bangkok 10330 Thailand \\ e-mail: pantawat.s@chula.ac.th
}

Received 29 Feb 2012

Accepted 19 Sep 2012

\begin{abstract}
This study analysed the effect of organic fertilizer on greenhouse gas emissions, including carbon dioxide $\left(\mathrm{CO}_{2}\right)$, methane $\left(\mathrm{CH}_{4}\right)$ and nitrous oxide $\left(\mathrm{N}_{2} \mathrm{O}\right)$, resulting from paddy field farming. Suphanburi 1 rice varieties were planted in a double-crop organic rice field at Pathum Thani Rice Research Centre, Pathum Thani Province, Thailand. The paddy was divided into 4 plots, as follows: (1) control plots without added fertilizer, (2) plots with the addition of organic fertilizer (cow manure), (3) plots with the addition of organic fertilizer pellets, and (4) plots with the addition of chemical fertilizers. The results showed that the $\mathrm{CO}_{2}, \mathrm{CH}_{4}$, and $\mathrm{N}_{2} \mathrm{O}$ emission rates in the chemical fertilizer plot were the highest at 534, 1.79, and $1.21 \mathrm{mg} \mathrm{m}^{-2}$ day $^{-1}$, respectively. The second highest levels were with the addition of manure at $377,1.35$, and $0.88 \mathrm{mg} \mathrm{m}^{-2} \mathrm{day}^{-1}$, respectively. To help reduce greenhouse gas emissions from rice farming, it is recommended that organic fertilizer be used instead of chemical fertilizer, a practice that will also benefit the farmers' health.
\end{abstract}

KEYWORDS: carbon dioxide, methane, nitrous oxide, chemical fertilizer

\section{INTRODUCTION}

The 'greenhouse effect' means the increase of average air temperatures due to an increase in concentration of atmospheric gases which absorb heat radiation through human activity. The six main types of greenhouse gases are: carbon dioxide $\left(\mathrm{CO}_{2}\right)$, methane $\left(\mathrm{CH}_{4}\right)$, nitrous oxide $\left(\mathrm{N}_{2} \mathrm{O}\right)$, hydrofluorocarbons (HFCs), perfluorocarbons (PFCs), and sulphurhexafloride $\left(\mathrm{SF}_{6}\right)^{1}$, which result from both industrial and agriculture activities. According to the report of The Greenhouse Gas Management Organization, which calculated the amount of greenhouse gases in the year 2000, Thailand, as an agricultural country, is a large contributor to the global greenhouse gas levels. The study showed that the amount of $\mathrm{CO}_{2}$ emitted by the transport sector was 229 million tons ${ }^{2}$, constituting $69.9 \%$ of the total amount of greenhouse gases, whereas the agricultural sector ranked second for greenhouse gas production, contributing $22.6 \%$. The report also found that paddy fields were the highest producers of greenhouse gases in the agricultural sector, accounting for $57.7 \%$ of total gases ${ }^{2}$.

Greenhouse gases generated from paddy field activity include $\mathrm{CO}_{2}, \mathrm{CH}_{4}$, and $\mathrm{N}_{2} \mathrm{O}$. The $\mathrm{CO}_{2}$ from farming results from rice photosynthesis and respiration, the soil microbes and the loss of soil organic carbon. Because $\mathrm{CH}_{4}$, per volume, absorbs infrared rays more easily than $\mathrm{CO}_{2}, \mathrm{CH}_{4}$ is the most prevalent greenhouse gas emission in the agricultural sector, as it evolves under anaerobic conditions and through organic decomposition. Nitrous oxide results from the general use of nitrogen fertilizers, which decompose into $\mathrm{N}_{2} \mathrm{O}$ through the denitrification process caused by flooding ${ }^{3}$.

This study focused on the use of organic fertilizers in paddy fields to reduce global warming by reducing greenhouse gas emission. The main issues of this study are in accordance with the Thailand government's policy to develop ways to reduce the contribution of paddy farming to global warming. The results of this study can be applied to other countries in efforts to reduce greenhouse gas emissions from paddy farming.

\section{MATERIALS AND METHODS}

\section{Experimental design}

Paddy field plot preparations: Organic paddy fields belonging to the Pathum Thani Rice Research Centre, Pathum Thani Province, Thailand, were used for the experiment. Each plot was $20 \times 20 \mathrm{~m}$. Preparation of the area involved removing rice stubble, ploughing to a depth not exceeding $30 \mathrm{~cm}$ and constructing a 
ridge in each plot to prevent the contamination or flooding from adjacent plots. Out-of-season rice was then planted by transplanting rice seedlings.

Seedling preparation: Provided by Rice Department, Ministry of Agriculture and Cooperatives, seeds of the Suphanburi 1 variety, which is uniform in seed size and weight, that were not contaminated and $80 \%$ sprouted were selected. The seeds were soaked in water for $12 \mathrm{~h}$ then covered with gunny sacks for 2 nights. The seeds that sprouted were sowed into small plots, with a sowing ratio of $50 \mathrm{~g} / \mathrm{m}^{3}$. The seeds were maintained for 25-30 days until the rice sprouted, and the seedlings were harvested and transplanted to the experimental plots.

Fertilizer preparation: The fertilizers used included organic fertilizer (cow manure), obtained from noncontaminated sources in the Pathum Thani area; pellet organic fertilizer; and chemical fertilizer (formulas 16-20-0 and 46-0-0), purchased from a market in Pathum Thani Province. A random sampling of all of the fertilizers was performed to analyse for acidforming or non-acid forming properties, $\mathrm{pH}$, moisture content, total nitrogen, the $\mathrm{C} / \mathrm{N}$ ratio and total organic carbon.

Rice planting and maintenance: The rice planting was divided into 2 stages: the first stage was to plant seeds in small plots by sowing the paddy seeds and allowing them to sprout in approximately 25-30 days; the second stage was to harvest and replant into experimental plots. A water level of $5-10 \mathrm{~cm}$ was maintained throughout the experiment.

Fertilizer application: The conditions for each experimental plot were as follows: (1) no added fertilizer; (2) organic fertilizer (cow manure) added during the plot preparation at a rate of $3.13 \mathrm{t} / \mathrm{ha}$, at 60 days after rice transplantation at a rate of $1.88 \mathrm{t} / \mathrm{ha}$ and the addition of $1.25 \mathrm{t} / \mathrm{ha}$ at the maturation and panicleformation stages; (3) initially adding pellet organic fertilizer during the paddy field preparation at a rate of $0.13 \mathrm{t} / \mathrm{ha}$, adding pellet organic fertilizer at the vegetative stage at a rate of $0.13 \mathrm{t} / \mathrm{ha}$ or after 60 days of transplanting the rice seedlings and adding pellet organic fertilizer at a rate of $0.06 \mathrm{t} / \mathrm{ha}$ at the maturation stage, and (4) adding chemical fertilizer, formula 16$20-0$, during the initial stage at a rate of $0.19 \mathrm{t} / \mathrm{ha}$ and adding chemical fertilizer formula 46-0-0 at a rate of $0.05 \mathrm{t} / \mathrm{ha}$ at the vegetative stage and $0.05 \mathrm{t} / \mathrm{ha}$ at the maturation stage.

\section{Sample collection and analysis}

The soil, water and air were sampled during the following 5 stages: before planting, initial stage, vegetative stage, panicle-formation stage, and maturation stage.

Soil sampling: Soil samples were randomly collected from each plot at 3 sample points, and a composite was created that was divided into 2 parts. One portion was dried at room temperature for $2-3 \mathrm{~h}$ and analysed prior to planting; the analytical parameters included the soil texture, moisture, $\mathrm{pH}$, cation exchange capacity, electrical conductivity, organic matter, oxidation-reduction potential, nitrogen, phosphorus, and potassium. The other portions of the samples were dried at $105^{\circ} \mathrm{C}$ for $24-48 \mathrm{~h}$ and ground and sieved using a $2 \mathrm{~mm}$ mesh size to analyse the total organic carbon.

Water sampling: Samples of the flood water in the paddy field and the temperature levels were collected. The water samples were collected in $1000 \mathrm{ml}$ containers and analysed before the planting stage. The analytical parameters included the biochemical oxygen demand, dissolved oxygen, $\mathrm{pH}$, electrical conductivity, and oxidation-reduction potential.

Air sampling: Air samples were collected in chambers using the following sampling method. The chamber used was $0.6 \mathrm{~m}$ wide, $0.6 \mathrm{~m}$ long, and $0.8 \mathrm{~m}$ high, with a volume of $0.29 \mathrm{~m}^{3}$. Three chambers per plot were distributed. Air samples were taken during the following stages: before planting the rice, initial stage, vegetative stage, panicle-formation stage, and maturation stage. These chambers were operated from $8.00-11.00$ in the morning during which an air pump drew in an air which was stored in a sample bag. The air samples were analysed for $\mathrm{CO}_{2}$ and $\mathrm{CH}_{4}$ using gas chromatography, and $\mathrm{N}_{2} \mathrm{O}$ was analysed using Fourier transform infrared spectroscopy. The concentration of greenhouse gas was determined from flux using the following equation ${ }^{4}$ :

$$
F_{i}=\frac{V_{\mathrm{std}} \Delta y_{i} M_{i}}{V_{\mathrm{m}} A \Delta t}
$$

where $F_{i}$ is the flux for gas $i, M_{i}$ is the molar mass of gas $i, A$ is the cross-section area of the box, $\Delta y_{i}$ is the change of concentration (amount fraction) of gas $i$ during contact time $\Delta t, V_{\mathrm{m}}$ is the molar volume of air at $0{ }^{\circ} \mathrm{C}$ and $760 \mathrm{mmHg}$, assumed to be $22.4 \mathrm{l} / \mathrm{mol}$, and $V_{\text {std }}$ was calculated as:

$$
V_{\mathrm{std}}=V \frac{(p / 760 \mathrm{mmHg})}{(T / 273 \mathrm{~K})},
$$


with $V$ the volume inside the plastic box at a point located above the flooding level, $p$ the ambient pressure at that time, and $T$ the absolute temperature of the air in the box.

\section{Statistical analysis}

Variation of $\mathrm{CO}_{2}, \mathrm{CH}_{4}$, and $\mathrm{N}_{2} \mathrm{O}$ emission data from the experiment was analysed using ANOVA, and the differences of the data were compared using Duncan's new multiple range test (DMRT). The statistical analysis was implemented using statistical package for the social science (SPSS).

\section{RESULTS AND DISCUSSION}

\section{Soil chemical and physical properties}

Soil chemical and physical properties before the experiment are shown in Table 1. The tests found the $\mathrm{pH}$ of the soil suitable for agriculture, especially for paddy cultivation. The Department of Agriculture specifies that a $\mathrm{pH}$ value of 5.0-6.5 is suitable for farming using irrigated cultivation ${ }^{5}$. In addition, electrical conductivity indicated that salinity would not affect the crop as it registered $4 \mathrm{dS} / \mathrm{m}$. The organic matter present was higher than the $2 \%^{6}$ that is considered plentiful for paddy field.

Table 1 shows the results of the soil chemical and physical properties for each plot during the growth of the rice. The chemically fertilized plots demonstrated an increasing $\mathrm{pH}$ from 4.27-7.08, indicating a strong acid condition that may have been caused by the added chemical fertilizer. Thus the chemical fertilizers might cause ammonium accumulation in the soil, generating $\mathrm{H}^{+}$from the nitrification process. Electrical conductivity is a value that indicates the amount of salt dissolved as ions in the water ${ }^{7}$. Conductivity is an index indicating the draw of salinity, nutrients and plant growth ${ }^{8}$. The results indicated that the electrical conductivity was in the range of $202-849 \mu \mathrm{S} / \mathrm{cm}$; the cation exchange capacity was in a range of $21.6-25.6 \mathrm{cmol}_{\mathrm{c}} / \mathrm{kg}$. The oxidationreduction potential, an indicator of the oxidationreduction state of the soil, was also determined. Normally, the decomposition of organic matter in soil caused by microbiological activity is due to oxidation reactions that release electrons, with oxygen and other compounds in the soil acting as oxidizing agents (via reduction reaction). The soil in wetlands shows a rapid decrease of oxygen due to the microbiological activity that consumes oxygen during growth. Hence, the soil in wetlands is identified as anaerobic, a condition affecting the chemical and biochemical processes when compared to aerobic soils. In addition, the range
Table 1 Physical and chemical properties of soil in paddy field at all stages of rice growth.

\begin{tabular}{|c|c|c|c|c|}
\hline $\begin{array}{l}\text { Stage of rice } \\
\text { growth/plot }\end{array}$ & $\mathrm{pH}$ & $\begin{array}{c}\sigma \\
(\mu \mathrm{S} / \mathrm{cm})\end{array}$ & $\begin{array}{c}\mathrm{CEC} \\
\left(\mathrm{cmol}_{\mathrm{c}} / \mathrm{kg}\right)\end{array}$ & $\begin{array}{l}\text { ORP } \\
(\mathrm{mV})\end{array}$ \\
\hline \multicolumn{5}{|c|}{ Before planting } \\
\hline C plots & 5.37 & 453 & 24.8 & 111.4 \\
\hline A plots & 5.39 & 647 & 24.8 & 96.9 \\
\hline B plots & 5.45 & 451 & 24.5 & 100.7 \\
\hline R plots & 4.31 & 1299 & 24.9 & 351.4 \\
\hline \multicolumn{5}{|l|}{ Initial stage } \\
\hline C plots & 5.54 & 413 & 24.6 & 87.9 \\
\hline A plots & 5.17 & 469 & 25.6 & 367 \\
\hline B plots & 6.49 & 381 & 21.6 & 204 \\
\hline $\mathrm{R}$ plots & 4.27 & 849 & 24.2 & 409.1 \\
\hline \multicolumn{5}{|c|}{ Vegetative stage } \\
\hline C plots & 6.47 & 265 & 23.6 & -41.5 \\
\hline A plots & 7.08 & 353 & 25.1 & -184.7 \\
\hline B plots & 6.85 & 323 & 23.3 & -71.9 \\
\hline R plots & 7.08 & 849 & 23.4 & -151.8 \\
\hline \multicolumn{5}{|c|}{ Panicle-formation stage } \\
\hline C plots & 4.81 & 478 & 22.8 & 285 \\
\hline A plots & 5.39 & 285 & 23.3 & 165 \\
\hline B plots & 4.84 & 370 & 24.9 & 228 \\
\hline R plots & 5.87 & 253 & 24.0 & 199 \\
\hline \multicolumn{5}{|c|}{ Maturation stage } \\
\hline C plots & 5.67 & 213 & 23.8 & 124 \\
\hline A plots & 6.14 & 202 & 24.2 & 155 \\
\hline B plots & 5.29 & 282 & 24.7 & 100 \\
\hline R plots & 6.26 & 265 & 23.2 & 110 \\
\hline
\end{tabular}

$\sigma$ : electrical conductivity; CEC: cation exchange capacity; ORP: oxidation-reduction potential.

C plots: control plots without added fertilizer.

A plots: plots with the addition of organic fertilizer (cow manure).

B plots: plots with the addition of organic fertilizer pellets.

R plots: plots with the addition of chemical fertilizer.

of oxidation-reduction potential is $-184.7-409.1 \mathrm{mV}$. The minus value results from the anaerobic condition of soils that have been long used for rice cultivation and results in conditions of oxygen deficiency, greatly reducing the oxidation-reduction potential ${ }^{9}$. Furthermore, the correlation of the oxidation-reduction potential was inversely related to the $\mathrm{pH}$. Thus increasing the $\mathrm{pH}$ decreased the oxidation-reduction potential ${ }^{9}$. In addition, the total carbon of the soil, which is organic and generated from both fertilizer and the decomposition of other organic matter in the soil, in each plot and each stage of rice growth was in a range of $23.1-37.4 \mathrm{~g} / \mathrm{kg}$. 


\section{Water chemical and physical properties}

The results of the water sample analysis before planting and transplanting the rice seedlings (Table 2) demonstrated that the $\mathrm{pH}$ was in the standard range for irrigation channels of between 6.5 and $8.5^{10}$. Study of the electrical conductivity indicated that the water contained inorganic matter and mostly dissolved salts dissociated as ions. Oxidation-reduction potential indicated that the water in all of the experimental plots contained dissociated ions ${ }^{11}$, dissolved oxygen concentrations, and a biological oxygen demand which conform to the standards for discharged wastewater from irrigation channels. This standard specifies that the biological oxygen demand should not exceed $20 \mathrm{mg} / \mathrm{l}^{10}$.

Table 2 shows the results of the chemical and physical properties of the water in all of the experimental plots during rice growth. The $\mathrm{pH}$ of the water was in the range of 6.34-8.21, and the electrical conductivity ranged from $223-1430 \mu \mathrm{S} / \mathrm{cm}$. These high values may have been due to the initial water flow in the paddy field causing inorganic substances to be removed, which increased the electrical conductivity ${ }^{12}$. The oxidation-reduction potentials were in a range of 149.3-229.9 mV. Dissolved oxygen levels were at $2-12 \mathrm{mg} / \mathrm{l}$, and the highest level was found under the pellet organic fertilizer treatment, as caused by the composition of nitrogen in a nitrate-nitrogen form and phosphorus in a phosphate-phosphorus form and dissolved inorganic substances ${ }^{12}$. This study found that the biochemical oxygen demand was in a range of $4.3-44 \mathrm{mg} / \mathrm{l}$ and slightly increased during the panicle-formation stage because the microorganisms require oxygen at high levels to decompose organic substances. These effects of a high biochemical oxygen demand correspond previous research that found that the residual material from paddy fields, such as muck, trash plant or trash grass and feed fermentation, result in water pollution ${ }^{13}$. The decomposition of plants and the effect of decreasing the dissolved oxygen result in biotic-dead water. The total carbon in the water ranged between 17.5 and $55.1 \mathrm{mg} / \mathrm{l}$.

\section{Quantity of greenhouse gas emission}

Different fertilizers were used for the experiment: organic fertilizer (cow manure), pellet organic fertilizer and chemical fertilizer (formulas 16-20-0 and 46-0-0). Both the organic fertilizer (cow manure) and pellet organic fertilizer, composed of nitrogen, phosphorus, and potassium (N:P:K), were expected to affect the greenhouse gas emissions due to agricultural activity. The overall analysis concluded that the $\mathrm{CO}_{2}$,
Table 2 Physical and chemical properties of water in paddy fields at all stages of rice growth.

\begin{tabular}{|c|c|c|c|c|c|}
\hline $\begin{array}{l}\text { Stage of rice } \\
\text { growth/plots }\end{array}$ & $\mathrm{pH}$ & $\begin{array}{c}\sigma \\
(\mu \mathrm{S} / \mathrm{cm})\end{array}$ & $\begin{array}{l}\text { ORP } \\
(\mathrm{mV})\end{array}$ & $\begin{array}{c}\mathrm{DO} \\
(\mathrm{mg} / \mathrm{l})\end{array}$ & $\begin{array}{l}\mathrm{BOD} \\
(\mathrm{mg} / \mathrm{l})\end{array}$ \\
\hline \multicolumn{6}{|c|}{ Before planting } \\
\hline C plots & 4.91 & 1970 & 239 & 4.0 & 2.9 \\
\hline A plots & 4.47 & 2230 & 225 & 5.8 & 2.2 \\
\hline B plots & 4.92 & 1950 & 230 & 5.1 & 2.5 \\
\hline R plots & 6.86 & 690 & 174 & 6.0 & 2.3 \\
\hline \multicolumn{6}{|l|}{ Initial stage } \\
\hline C plots & 7.39 & 860 & 150.1 & 5.67 & 4.3 \\
\hline A plots & 7.09 & 890 & 190.3 & 5.14 & 5.2 \\
\hline B plots & 6.59 & 1100 & 176 & 5.61 & 5.6 \\
\hline $\mathrm{R}$ plots & 6.53 & 1430 & 180.4 & 6.59 & 4.7 \\
\hline \multicolumn{6}{|c|}{ Vegetative stage } \\
\hline C plots & 6.69 & 542 & 198.7 & 7.76 & 5.9 \\
\hline A plots & 7.19 & 545 & 217 & 6.91 & 6.4 \\
\hline B plots & 8.21 & 568 & 174.2 & 12.1 & 14 \\
\hline R plots & 6.42 & 631 & 229.9 & 2.05 & 21 \\
\hline \multicolumn{6}{|c|}{ Panicle-formation stage } \\
\hline C plots & 7.53 & 636 & 155.4 & 3.14 & 30 \\
\hline A plots & 6.84 & 610 & 167.4 & 3.01 & 44 \\
\hline B plots & 7.07 & 633 & 149.3 & 6.23 & 24 \\
\hline R plots & 7.04 & 591 & 154.7 & 5.13 & 39 \\
\hline \multicolumn{6}{|c|}{ Maturation stage } \\
\hline C plots & 6.66 & 223 & 172.1 & 4.43 & 12 \\
\hline A plots & 6.56 & 230 & 175.7 & 4.52 & 13 \\
\hline B plots & 6.34 & 314 & 223.1 & 5.87 & 12 \\
\hline R plots & 6.50 & 226 & 220.6 & 5.05 & 13 \\
\hline
\end{tabular}

$\sigma$ : electrical conductivity; ORP: oxidation-reduction potential; DO: dissolved oxygen concentration; BOD: biological oxygen demand.

C plots: control plots without added fertilizer.

A plots: plots with the addition of organic fertilizer (cow manure).

B plots: plots with the addition of organic fertilizer pellets.

R plots: plots with the addition of chemical fertilizer.

$\mathrm{CH}_{4}$, and $\mathrm{N}_{2} \mathrm{O}$ were emitted at statistically significant differences $(p<0.05)$. Detail of the greenhouse gas emission is shown in Table 3.

$\mathrm{CO}_{2}$ emission: Fig. 1a shows the quantity of $\mathrm{CO}_{2}$ emission. Paddy fields with the added chemical fertilizer emitted the most $\mathrm{CO}_{2}$ gas, averaging $534.11 \mathrm{mg}$ $\mathrm{m}^{-2}$ day $^{-1}$. The lowest was found in the paddy fields that contained added organic fertilizer (cow manure). The organic fertilizer plot, pellet organic fertilizer plot, and control plot emitted $\mathrm{CO}_{2}$ gas at rates of $377.35,272.56$, and $269.72 \mathrm{mg} \mathrm{m}^{-2} \mathrm{day}^{-1}$, respectively. While these rates were not significantly 
Table 3 Quantity of greenhouse gas emission after fertilizer application in plots.

\begin{tabular}{lcc}
\hline Plots & \multicolumn{2}{c}{ Emission of greenhouse gas $\left(\mathrm{mg} \mathrm{m}^{-2}\right.$ day $\left.^{-1}\right)$} \\
\cline { 2 - 3 } & $\mathrm{CO}_{2}$ & $\mathrm{CH}_{4}$ \\
\hline C Plots & $270 \pm 40^{\mathrm{a}}$ & $1.20 \pm 0.16$ \\
A Plots & $377 \pm 28^{\mathrm{a}}$ & $1.35 \pm 0.3$ \\
B Plots & $273 \pm 33^{\mathrm{a}}$ & $1.28 \pm 0.18$ \\
R Plots & $534 \pm 109^{\mathrm{b}}$ & $1.79 \pm 0.28$ \\
\hline
\end{tabular}

Mean \pm SEM, $n=3$. Numbers followed by the same letter in each column are not significantly different at $p<0.05$ using DMRT.

C plots: control plots without added fertilizer.

A plots: plots with the addition of organic fertilizer (cow manure).

B plots: plots with the addition of organic fertilizer pellets.

R plots: plots with the addition of chemical fertilizer.
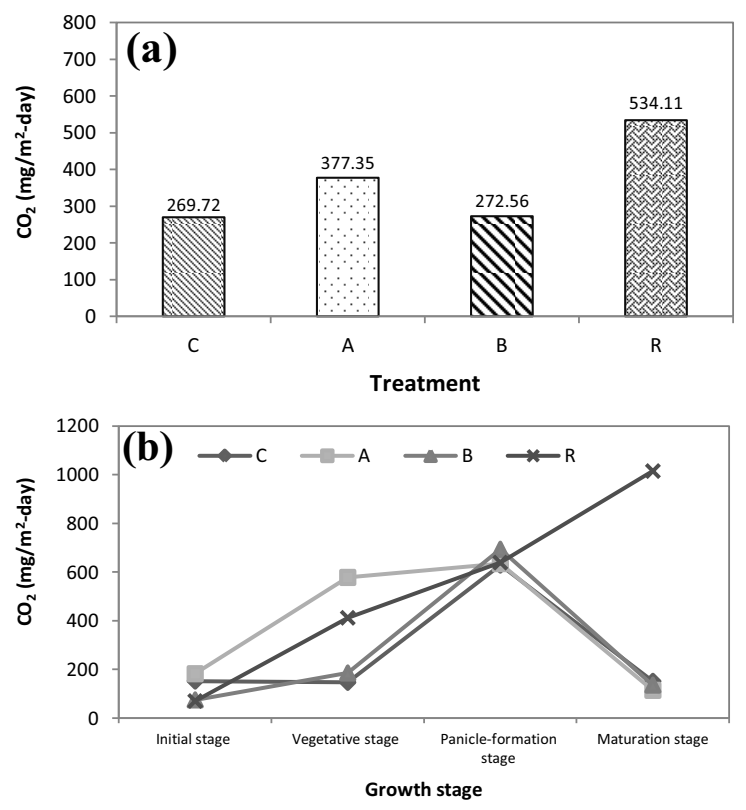

Fig. 1 CO2 quantity: (a) $\mathrm{CO}_{2}$ quantity in each plot and (b) $\mathrm{CO}_{2}$ quantity in every plot throughout the rice growth period. C, control plots without added fertilizer; A, plots with the addition of organic fertilizer (cow manure); B, plots with the addition of organic fertilizer pellets; R, plots with the addition of chemical fertilizer.

different statistically the results of this study indicate that the addition of fertilizer in paddy fields does increase the $\mathrm{CO}_{2}$ emission rates and may need further study.

The $\mathrm{CO}_{2}$ emission is generated by organic decomposition in the soil under aerobic conditions. Hence, a high quantity of organic matter is an important factor in increasing $\mathrm{CO}_{2}$ emissions, which corresponds to Tattao ${ }^{14}$ who studied the total density of fertilizer by varying the ratio for agriculture: the $\mathrm{N}: \mathrm{P}_{2} \mathrm{O}_{5}$ ratio was varied at a level of 9.6:9.6 and 28.8:28.8, and the results indicated that the soil density increases from $1.15 \mathrm{~g} / \mathrm{m}^{3}$ to $1.47 \mathrm{~g} / \mathrm{m}^{3}$ when the ratio is increased. When adding fertilizer to the soil, both the nitrogen and soil density will increase. In the present study, the quantity of $\mathrm{CO}_{2}$ in each plot experiment found that $\mathrm{CO}_{2}$ emitted through rice plant. The panicleformation stage displayed the highest $\mathrm{CO}_{2}$ level, after the plot with added chemical fertilizer, which, as illustrated in Fig. 1b, had the highest $\mathrm{CO}_{2}$ emission during the harvest period. This finding corresponds to Redeker's ${ }^{15}$ research, which indicated that plants of the Chainat variety had the highest emission rate (539.6 $\mathrm{mg} \mathrm{m}^{-2}$ day $^{-1}$ ) during the panicle-formation stage.

$\mathrm{CH}_{4}$ emissions: The $\mathrm{CH}_{4}$ emission quantity (Fig. 2a) shows that adding fertilizer in each plot effected the $\mathrm{CH}_{4}$ emissions. The highest rate of $\mathrm{CH}_{4}$ emission occurred in the plot with the added chemical fertilizer and measured an average rate of $1.79 \mathrm{mg}$ $\mathrm{m}^{-2}$ day $^{-1}$. The plot with the added organic fertilizer (cow manure) and organic fertilizer pellets emitted $\mathrm{CH}_{4}$ at the average rate of 1.35 and $1.28 \mathrm{mg} \mathrm{m}^{-2}$ day $^{-1}$, respectively. In addition, the control plot emitted the lowest $\mathrm{CH}_{4}$ level, at the rate of $1.20 \mathrm{mg}$ $\mathrm{m}^{-2}$ day $^{-1}$. All of the $\mathrm{CH}_{4}$ emission rates in all of the plots showed differences that were not statistically significant. Most of the methane emitted by the paddy field was generated by the microbiological decomposition in the soil. It was also found that the rice in each growth stage has a statistically significant difference in the emission rate $(p<0.05)$. When compared with the methane emission rate of each plot during the rice growth stages, we found that the rice in the vegetative stages had the highest emission rate, with a statistically significant difference $(p<0.05)$. In addition, the plot with the added chemical fertilizer had the highest methane emission rate, at $3.03 \mathrm{mg}$ $\mathrm{m}^{-2}$ day $^{-1}$. The ranking order for the methane emission rate is the plot with added organic fertilizer pellets, the organic fertilizer (cow manure) and the control plot, at $2.88,1.68$, and $1.03 \mathrm{mg} \mathrm{m}^{-2}$ day $^{-1}$, respectively. A similar study by Ying and Tai ${ }^{16}$ evaluated the methane emission from pre-germinated direct-seeded lowland rice of different seed varieties combined with water management and chemical fertilizer addition during out-of-season rice growth. The results of the present study showed that the 

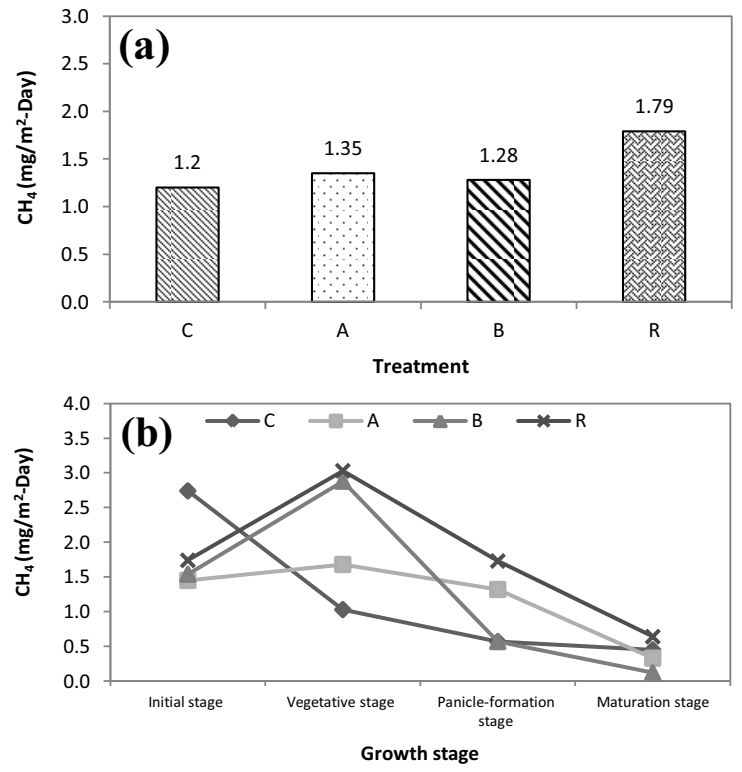

Fig. 2 Methane quantity: (a) methane quantity in each plot and (b) methane quantity in all plots throughout rice growth. Labels as in Fig. 1.

highest methane emission rate was generated during the plant growth between 16 and 40 days or by rice in the vegetative stage (Fig. 2b).

$\mathrm{N}_{2} \mathrm{O}$ emission: The control plot, added organic fertilizer (cow manure) plot and organic fertilizer pellet plot emitted $\mathrm{N}_{2} \mathrm{O}$ at averages of $0.27,0.88$, and $0.42 \mathrm{mg} \mathrm{m}^{-2}$ day $^{-1}$, respectively. The plot with added chemical fertilizer emitted the most $\mathrm{N}_{2} \mathrm{O}$ during the rice season, at a rate of $1.21 \mathrm{mg} \mathrm{m}^{-2}$ day $^{-1}$ (Fig. 3a). In addition, adding fertilizer increased the $\mathrm{N}_{2} \mathrm{O}$ emissions, a finding that was especially noted in the plot with the chemical fertilizer. The $\mathrm{N}_{2} \mathrm{O}$ emission was directly affected by the chemical fertilizer component, the N:P:K ratio of 16:20:0 and 46:0:0, which corresponds to Stevenson and Cole ${ }^{17}$ who studied the use of fertilizer with a high nitrogen component in agriculture, reporting higher amounts of $\mathrm{N}_{2} \mathrm{O}$ emissions. Moreover, the comparison of the $\mathrm{N}_{2} \mathrm{O}$ emission rate during each rice growth stage found that the plants in the vegetative stage emitted the highest amount of $\mathrm{N}_{2} \mathrm{O}$ (Fig. 3b). In addition, newly germinated rice seedlings depend on large quantities of nutrients for strong and complete ${ }^{18}$ growth. Hence, fertilizer formula 46-0-0 was added to the paddy field, and the results showed that the $\mathrm{N}_{2} \mathrm{O}$ emission was the highest during the vegetative stage because the high quantity of nitrogen in the fertilizer increased the $\mathrm{N}_{2} \mathrm{O}$ emission rate.
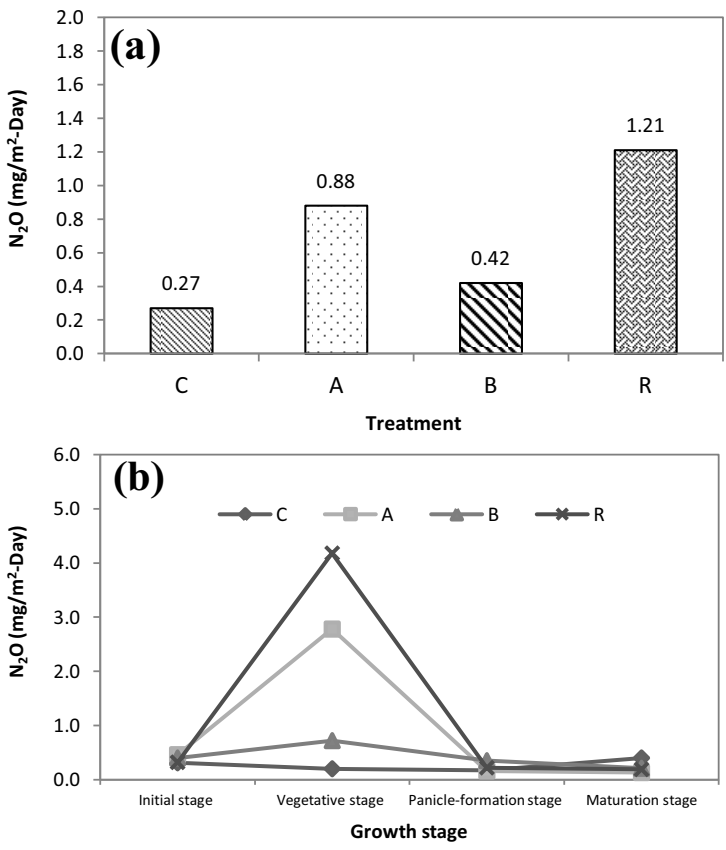

Fig. 3 Nitrous oxide quantity: (a) nitrous oxide quantity in each plot and (b) nitrous oxide quantity in all plots throughout rice growth. Labels as in Fig. 1.

The application of fertilizer increased the greenhouse gas emission during rice cultivation. The plot with the added chemical fertilizer formulas, 1620-0 and 46-0-0, which are considered appropriate for rice growth ${ }^{19}$, increased some of the greenhouse gas emissions. The highest levels of $\mathrm{CO}_{2}$ emission $(36.74 \%)$, methane emission $(31.85 \%)$, and $\mathrm{N}_{2} \mathrm{O}$ $(43.53 \%)$ of the total greenhouse gas emissions during rice growth are illustrated in Table 4 . The application of chemical fertilizer caused higher greenhouse gas emissions than the organic fertilizer because chemical fertilizers indirectly affect soil reactions increasing the amount of methane that will be emitted ${ }^{20}$. In addition, the denitrification process will be initiated, whereby nitrate is converted to nitrogen gas under anaerobic conditions by microorganisms in the soil ${ }^{21}$.

We conclude that to reduce greenhouse gas emissions in paddy field farming, agriculturists should add organic fertilizer instead of chemical fertilizer. This would also afford benefits to the health of the agriculturists. However, it may be difficult for them to switch to organic fertilizer because chemical fertilizer results in good production and many individuals neglect to consider the negative effects on the environment. Based on this study, the highest rice production occurred under the treatment of added organic fertilizer (cow manure), and the remaining 
Table 4 Percent of greenhouse gas emission.

\begin{tabular}{lcc}
\hline Plots & \multicolumn{2}{c}{ Emission of greenhouse gas $(\%)$} \\
\cline { 2 - 3 } & $\mathrm{CO}_{2}$ & Methane \\
\hline C Plots & 36.74 & 21.35 \\
A Plots & 25.96 & 24.02 \\
B Plots & 18.75 & 22.78 \\
R Plots & 18.55 & 31.85 \\
Total & 100 & 100 \\
\hline
\end{tabular}

C plots: control plots without added fertilizer.

A plots: plots with the addition of organic fertilizer (cow manure).

B plots: plots with the addition of organic fertilizer pellets.

$\mathrm{R}$ plots: plots with the addition of chemical fertilizer.

ranking order was paddy fields with added chemical fertilizer, pellet organic fertilizer and the control plots, respectively; the production for each field was 3.59, $3.34,2.71$, and $2.00 \mathrm{t} / \mathrm{ha}$, respectively. To promote the use of organic fertilizer, relevant agencies should provide information that is relevant to environmental effects and health impacts on both the producer and consumer. Moreover, such guidance for the reduction of greenhouse gases due to agriculture should be provided for acceptance by the agriculturist in addition to the consideration of rice production. Furthermore, agriculturists should be encouraged to use organic fertilizer, as it results in the reduction of greenhouse gas emissions from agriculture and is considered as part of the Clean Development Mechanism for Thailand to reduce greenhouse gas emission. In addition, because agriculturist is a major occupation throughout Thailand, the reduction of greenhouse gas emissions could result in carbon credit trading that could provide high revenues for Thailand. Additionally, organic fertilizer is more efficient in enriching the soil, promotes soil aeration and looseness and contains more and varied nutrients than chemical fertilizer ${ }^{22}$. Furthermore, modifications of water management by adding a small amount of water and draining when the rice plants reach the vegetative stage and then allowing evaporation as a natural process complies with the study of Tsuruta and Hirose ${ }^{23}$ and results in the reduction of methane and $\mathrm{N}_{2} \mathrm{O}$ production.

\section{CONCLUSIONS AND RECOMMENDATIONS}

\section{Effect of fertilizer on the quantity of greenhouse gas emission}

The quantity of greenhouse gas emitted from the experimental plots indicated that paddy field with added chemical fertilizer had the highest emission rates when compared to all of the plots. The greenhouse gases in this study were $\mathrm{CO}_{2}$, methane and $\mathrm{N}_{2} \mathrm{O}$, and the emission rates were $534.11,1.79$, and $1.21 \mathrm{mg}$ $\mathrm{m}^{-2}$ day $^{-1}$, respectively. The plot with the added organic fertilizer pellets had the lowest emission rates of $272.56,1.28$, and $0.42 \mathrm{mg} \mathrm{m}^{-2}$ day $^{-1}$, respectively. However, this plot had lower rice production than the plot with added organic fertilizer (cow manure). The greenhouse gas emission rates for each gas type and paddy field were statistically significant $(p<0.05)$.

\section{Effect of greenhouse gas emission during rice growth}

The study of the greenhouse gas emission from the plots also compared each rice growth stage, with all of the fields emitting $\mathrm{CO}_{2}$ mostly during the panicleformation stage. Furthermore, during the vegetative stage, methane and $\mathrm{N}_{2} \mathrm{O}$ were mostly emitted by all of the plots; the drainage of water from the paddy fields after the vegetative stage resulted in decreased greenhouse gas emission in all of the plots. The lowest greenhouse gas emission rate for all stage was found prior to the harvest rice stage. The difference in each rice growth stage was statistically significant $(p<0.05)$.

\section{Guidance for the reduction of greenhouse gas emission from paddy field farming}

To reduce $\mathrm{CO}_{2}$, agriculturists should be encouraged to discard organic waste instead of burning, decrease ploughing and provide mostly $\mathrm{CO}_{2}$ in the carbon cycle in an organic form to slow organic decomposition and increase photosynthesis. For methane reduction, agriculturists should avoid adding large amounts of organic fertilizer, improve soil quality by increasing aeration and drain water from the paddies prior to the panicle-formation stage. For $\mathrm{N}_{2} \mathrm{O}$ reduction, farmers can add organic fertilizer instead of chemical fertilizer; however, organic fertilizer must also contain a low quantity of nitrate.

Finally, the application of organic fertilizer in agriculture, especially paddy field farming, would protect and conserve the environment through pollution prevention ( $\mathrm{P} 2)$ from non-point sources.

Acknowledgements: I would like to express my appreciation to the National Research University Project, Chulalongkorn University and the Office of the Higher Education Commission for supporting funds for CC320A project. Furthermore, I would like to thank the Pathum Thani Rice Research Centre for providing a site to conduct the experiment. Many thanks to the Environmental Research Institute and National Centre of Excellence for Environmental and 
Hazardous Waste Management, Chulalongkorn University for its support with tools and equipment and the Department of Science Service for providing support equipment and apparatus for this study.

\section{REFERENCES}

1. United Nations Framework Convention on Climate Change (2011) Kyoto Protocol [Online]. Available from: http://unfccc.int.

2. Thailand Greenhouse Gas Management Organization (2000) Greenhouse Gas in Thailand [Online]. Available from: http://www.ieat.go.th.

3. Shioiri M (1942) Denitrification in paddy soils. Journal Sci Soil Manu 16, 104-16.

4. Singh JS, Raghubanshi AS, Reddy VS, Singh S, Kashyap AK (1998) Methane flux from irrigated paddy and dryland rice fields, and from seasonally dry tropical forest and savanna soils of India. Soil Biol Biochem 30, 135-9.

5. Tilman D, Cassman KG, Matson PA, Naylor R, Polasky S (2002) Agricultural sustainability and intensive production practices. Nature 418, 671-7.

6. Ou SH (1985) Rice Diseases, 2nd edn, Los Baños, Laguna, Philippines.

7. Panswad T, Wisuttisak W (1997) Water Analysis. Bangkok: The Environmental Engineering Association of Thailand.

8. Bernard PK, Yerima E, Van R (2005) Introduction Soil Science: Soils of the Tropics. Oxford, UK.

9. Wiwutwongwana P (2003) Soil Chemistry. 500 Books. Print No 1. Chiang Mai: Chiang Mai Pem-soue, Chiand Mai, Thailand.

10. Department of Pollution Control (1997) Water Quality Criteria and Standards in Water Quality. Ministry of Natural Resources and Environment of Thailand.

11. Tanturavech M, Tanturavech M (2002) Chemistry of Water and Wastewater. Print No 1. Chulalongkorn Univ Printing House, Bangkok, Thailand.

12. Chun G, Yoon JH, Ham JH (2003) Mass balance analysis in Korean paddy rice culture. Paddy Water Environ 2, 99-106.

13. David P, Bonnie B, David F, Michelle N, Benjamin W, Elizabeth K, Steven C, Elaine P, Elizabeth A (2004) Water resources: Agricultural and environmental issues. BioScience 10, 909-18.

14. Tattao DA (1987) Influence of long-term N-P fertilizers, cropping systems and rainfall on corn yields and soil properties. Doctor's thesis, Kasetsart Univ, Bangkok, Thailand.

15. Redeker KR, Wang NY, Low JC, McMillan A, Tyler SC, Cicerone RJ (2000) Emissions of methyl halides and methane from rice paddies. Science 3, 966-9.

16. Ying YS, Tai XB (2003) Effects of rice plants on methane emission from paddy fields. Chin J Appl Ecol 11, 2049-53.

17. Stevenson FJ, Cole MA (1999) Cycles of Soil. Canada.
18. Ministry of Agriculture Cooperatives (2008) Integrated rice [Online]. Available from: http://www.brrd.in.th/ rkb.

19. Department of Agricultural Extension (2010) The Increasing of Rice Yield per Hectare. In the Meeting documents for registration of rice farmers, Bangkok, Thailand.

20. Thanyadee P, Maneewan M, Wananukool P (1997) Knowledge of Organic Matter in the Soil. Manual of the Improve soil with organic matter. Land Development Department, Bangkok, Thailand.

21. Nimrat S (2006) Soil Microbiology. Odeon Store, Bangkok, Thailand.

22. Wannai S (1978) Organic Fertilizer. Technology Promotion Association (Thailand-Japan), Bangkok, Thailand.

23. Tsuruta H, Kanda K, Hirose T (1997) Nitrous oxide emission from a rice paddy field in japan. Nutr $\mathrm{Cycl}$ Agroecosys 49, 51-8. 